\title{
CARACTERIZAÇÃO E ACEITABILIDADE DE BISCOITOS PREPARADOS COM FARINHA SEM GLÚTEN
}

\section{CHARACTERIZATION AND ACCEPTABILITY OF COOKIES PREPARED WITH GLUTEN-FREE FLOUR}

\author{
Cristine Giovanella ${ }^{1}$, Cláudia Schlabitz ${ }^{2}$, Claucia Fernanda Volken de Souza ${ }^{3}$ \\ ${ }^{1}$ Centro Universitário UNIVATES - Lajeado - Brasil cristinegiovanella@ universo.univates.br \\ ${ }^{2}$ Centro Universitário UNIVATES - Lajeado - Brasil cschlabitz@ univates.br \\ ${ }^{3}$ Centro Universitário UNIVATES - Lajeado - Brasil claucia@ univates.br
}

\begin{abstract}
Resumo
Os biscoitos representam uma alternativa prática de consumo de nutrientes, principalmente de carboidratos e proteínas, tendo em vista a facilidade de transporte e armazenamento, além da longa vida de prateleira. Por outro lado, os celíacos, pessoas com intolerância ao glúten, em função da oferta limitada de biscoitos sem glúten apresentam dificuldade de consumo desse alimento. O objetivo do presente trabalho foi elaborar e avaliar as características físico-químicas e sensoriais de biscoitos sem glúten. Foram elaboradas quatro diferentes formulações com farinha de quinua e fécula de batata, que foram submetidas às análises físico-químicas de determinação dos teores de umidade, cinzas, proteínas e lipídeos; e sensoriais de aceitação dos atributos aparência, sabor, textura e impressão global, além da intenção de compra. Os teores de cinzas, proteínas e lipídeos das quatro formulações elaboradas variaram entre 1,35-1,87\%, 5,04-7,68\% e 16,26-19,52\%, respectivamente. Os resultados do índice de aceitabilidade dos atributos aparência, sabor, textura e impressão global das quatro formulações de biscoitos sem glúten foram superiores a $71 \%$. A Formulação B com $31 \%$ de farinha de quinua e $21 \%$ de fécula de batata apresentou melhor aceitação na avaliação sensorial e 6,75\% de fibra alimentar total, sendo uma proposta viável para a elaboração de biscoitos sem glúten, possibilitando uma melhoria da qualidade alimentar da população celíaca através do incremento do aporte nutricional de fibra alimentar. Os resultados físico-químicos e sensoriais obtidos nesse estudo demonstraram a viabilidade de elaboração de biscoitos sem glúten com farinha de quinua e fécula de batata.
\end{abstract}

Palavras-chave: biscoitos; doença celíaca; análise sensorial.

\section{Introdução}

O Brasil ocupa a posição de $2^{\circ}$ maior produtor mundial de biscoitos, com o registro de 1.242 milhões de toneladas produzidas em 2010, que representou 3\% de crescimento em relação a 2009, quando a produção foi de 1.206 milhões de toneladas. Nos últimos anos o país também ampliou de forma significativa a comercialização no mercado internacional. A expectativa para 2011 é que as 
exportações superem os US\$ 120 milhões, o que representa um crescimento de $13 \%$ em relação ao ano de 2010 (SIMABESP, 2011; ANIB, 2011).

A longa vida de prateleira desse produto permite uma produção em grande quantidade, além de facilitar o processo de distribuição. Tendo em vista a facilidade de armazenamento e transporte, os biscoitos constituem uma alternativa prática de consumo de nutrientes como carboidratos e proteínas. Embora, não se caracterize num alimento básico como o pão, é aceito e consumido por pessoas de qualquer idade (GUTKOSKI et al., 2003).

O glúten é uma proteína encontrada nos cereais: trigo, aveia, centeio e cevada, composta pelas frações protéicas denominadas gliadina e glutenina, que na presença de água se hidratam, interagem e formam a rede de glúten, responsável pelas características funcionais de formação da massa. O glúten não é um componente que faz parte diretamente da composição desses cereais, é formado quando a farinha obtida a partir do cereal e a água, na presença ou não de outros ingredientes, são misturadas e sofrem a ação de um trabalho mecânico. As gliadinas são proteínas de cadeia simples, extremamente pegajosas, responsáveis pela consistência e viscosidade da massa, apresentando pouca resistência a extensão. As gluteninas apresentam cadeias ramificadas, sendo responsáveis pela extensibilidade da massa (CZUCHAJOWSKA e PASZCZYNSKS, 1996).

A doença celíaca é uma intolerância à ingestão do glúten, em indivíduos geneticamente predispostos, caracterizada por um processo inflamatório que envolve a mucosa do intestino delgado, levando a atrofia das vilosidades intestinais, má absorção e uma variedade de manifestações clínicas. As pessoas celíacas não podem consumir qualquer tipo de produto farináceo que contenha um destes cereais na sua composição (SILVA e FURLANETTO, 2010; SDEPANIAN et al., 1999). Apesar da produção significativa de biscoitos no Brasil, a oferta desse produto isento de glúten é muito limitada. Dessa forma, os celíacos apresentam dificuldade de consumo desse alimento, devido a pouca oferta de biscoitos sem glúten, principalmente com qualidade sensorial similar ao produto convencional.

A quinoa ou quinua é um pseudocereal pertencente à família Chenopodiaceae, do gênero Chenopodium, originário dos Andes. Apresenta um elevado teor protéico, em particular dos aminoácidos lisina e histidina; de fibras, que auxiliam no bom funcionamento do intestino e na redução da absorção de gorduras e açúcares; de minerais, principalmente de ferro e cálcio; e de vitaminas. Além disso, os lipídios da quinua são ricos nos ácidos graxos essenciais - linoléico e linolênico (SPEHAR, 2006; LOPES, 2009; ALMEIDA, 2009).

Portanto, o objetivo desse trabalho foi desenvolver e avaliar as características físicoquímicas e sensoriais de biscoitos sem glúten com farinha de quinua e fécula de batata. 


\section{Material e Métodos}

\section{Material}

Todos os ingredientes para a elaboração dos biscoitos foram adquiridos no comércio local da cidade de Lajeado, RS.

\section{Métodos}

\section{Elaboração dos biscoitos}

Os biscoitos foram produzidos na Padaria Espaço Doce no município de Nova Bréscia, RS.

A Tabela 1 apresenta as quatro formulações de biscoito sem glúten elaboradas com diferentes proporções de farinha de quinua e fécula de batata. Essas formulações foram genericamente denominadas de Formulação A, B, C e D e apresentavam as seguintes concentrações $(\mathrm{em} \% \mathrm{~m} / \mathrm{m})$ de farinha de quinua e fécula de batata, respectivamente, em relação à quantidade total de massa: 37:11; 31:21; 26:26; 18:38. A quantidade dos demais ingredientes: açúcar, manteiga, gema de ovo, ovo e fermento químico foram constantes em todas as formulações.

Tabela 1 - Formulações dos biscoitos sem glúten elaborados com farinha de quinua e fécula de batata

\begin{tabular}{ccccc}
\hline \multirow{2}{*}{ Ingredientes $(\mathbf{g})$} & \multicolumn{4}{c}{ Formulações } \\
\cline { 2 - 5 } & A & B & C & D \\
\hline Farinha de quinua & 325 & 300 & 250 & 190 \\
Fécula batata & 100 & 200 & 250 & 400 \\
Açúcar & 200 & 200 & 200 & 200 \\
Manteiga & 150 & 150 & 150 & 150 \\
Ovo & 55 & 55 & 55 & 55 \\
Gema de ovo & 35 & 35 & 35 & 35 \\
Fermento químico & 10 & 10 & 10 & 10 \\
\hline Total (g) & 875 & 950 & 950 & 1040 \\
\hline
\end{tabular}

Para a elaboração dos biscoitos, inicialmente, todos os ingredientes foram pesados em balança digital (modelo US 25/5, marca Urano). A seguir foram misturados os ingredientes secos: açúcar, fermento químico, farinha de quinua e fécula de batata. Em outro recipiente foram adicionados e misturados os demais ingredientes: gemas, ovo e manteiga. Após, todos os ingredientes foram misturados em batedeira (modelo planetária, marca G. Paniz) até a obtenção de uma massa homogênea, aproximadamente $10 \mathrm{~min}$. A massa dos biscoitos foi amassada manualmente, dividida em pequenas porções, para assim ser estendida com rolo de polietileno para massas. Em seguida, os biscoitos foram moldados com o auxílio de uma forma de alumínio. Todas 
as amostras foram assadas em forno turbo a lenha (modelo PRTL/2010, marca Pró-gás) a $150{ }^{\circ} \mathrm{C}$ durante $15 \mathrm{~min}$.

\section{Análises físico-químicas dos biscoitos}

A composição química das formulações dos biscoitos foi determinada através dos seguintes procedimentos: umidade em estufa a $105^{\circ} \mathrm{C}$ até peso constante, sais minerais por incineração a 550 ${ }^{\circ} \mathrm{C}$, lipídios pelo método de extração direta por solvente (Método de Soxleht) e proteínas através da determinação do teor de nitrogênio total pelo Método de Kjeldahl e convertido em proteína bruta pelo fator 6,25, conforme metodologias do Instituto Adolfo Lutz (IAL, 2005). O teor de carboidratos totais foi determinado pelo cálculo da diferença de 100 gramas de biscoito e a soma total dos valores encontrados para os componentes citados. A fibra alimentar da Formulação B foi determinada segundo Método 991.43 da AOAC (1995). Todas as análises foram realizadas em triplicata.

\section{Análise sensorial dos biscoitos}

A avaliação sensorial dos produtos foi realizada por 56 provadores não treinados, recrutados entre os estudantes da Univates, sendo 15 homens e 41 mulheres, com idades entre 25 e 50 anos. A avaliação sensorial dos biscoitos foi realizada no Laboratório de Análise Sensorial da Univates, em cabines individuais sob luz branca e a temperatura ambiente, com as amostras dispostas em prato branco de plástico. As amostras em porções padronizadas (aproximadamente $5 \mathrm{~g}$ ) foram codificadas com números aleatórios de três dígitos e apresentadas aos provadores de forma balanceada e aleatorizada. Junto com as amostras foi servida água mineral a temperatura ambiente para limpeza do palato e a ficha do teste contendo uma escala hedônica estruturada de nove pontos, variando de 1 “desgostei muitíssimo" a 9 "gostei muitíssimo". A análise sensorial, através do teste de aceitação, avaliou a preferência em relação aos atributos aparência, sabor, textura e impressão global do produto. Para avaliar a intenção de compra utilizou-se a escala de cinco pontos variando de 1 "certamente não compraria" a 5 "certamente compraria". Para determinar a aceitabilidade dos produtos foram calculados a frequência relativa das notas atribuídas pelos provadores na avaliação sensorial dos diferentes atributos e o índice de aceitabilidade das amostras de biscoitos, conforme Dessimoni-Pinto et al. (2010) e Peuckert et al. (2010).

O presente trabalho foi aprovado pelo Comitê de Ética em Pesquisa (COEP) da Univates sob o registro número $\mathrm{N}^{\circ} 144 / 10$.

\section{Análise estatística}


Os resultados das análises físico-químicas e sensoriais dos biscoitos foram avaliados pela Análise de Variância (ANOVA) e verificada a significância dos modelos pelo teste F. Nos modelos significativos, as médias foram comparadas entre si pelo teste de Tukey, ao nível de 5\% de significância, utilizando o software Statistica® versão 7.0.

\section{Resultados e Discussão}

\section{Análises físico-químicas dos biscoitos}

A Tabela 2 apresenta os resultados das análises físico-químicas dos biscoitos sem glúten elaborados com farinha de quinua e fécula de batata.

Tabela 2 - Resultados físico-químicos (em \%) dos biscoitos sem glúten elaborados com farinha de quinua e fécula de batata

\begin{tabular}{ccccc}
\hline \multirow{2}{*}{ Componente } & \multicolumn{4}{c}{ Formulações } \\
\cline { 2 - 5 } & $\mathbf{A}$ & $\mathbf{B}$ & $\mathbf{C}$ & $\mathbf{D}$ \\
\hline Umidade & $2,4 \pm 0,10^{\mathrm{d}}$ & $3,7 \pm 0,04^{\mathrm{a}}$ & $2,5 \pm 0,03^{\mathrm{c}}$ & $3,4 \pm 0,07^{\mathrm{b}}$ \\
Cinzas & $1,7 \pm 0,05^{\mathrm{a}}$ & $1,9 \pm 0,06^{\mathrm{a}}$ & $1,3 \pm 0,05^{\mathrm{b}}$ & $1,5 \pm 0,12^{\mathrm{b}}$ \\
Proteínas & $7,1 \pm 0,08^{\mathrm{b}}$ & $7,7 \pm 0,14^{\mathrm{a}}$ & $5,0 \pm 0,01^{\mathrm{c}}$ & $5,1 \pm 0,04^{\mathrm{c}}$ \\
Lipídios & $19,2 \pm 0,16^{\mathrm{a}}$ & $19,5 \pm 0,30^{\mathrm{a}}$ & $16,3 \pm 0,12^{\mathrm{c}}$ & $16,8 \pm 0,14^{\mathrm{b}}$ \\
Carboidratos & $69,6 \pm 0,24^{\mathrm{c}}$ & $67,2 \pm 0,18^{\mathrm{d}}$ & $74,8 \pm 0,18^{\mathrm{a}}$ & $73,1 \pm 0,19^{\mathrm{b}}$ \\
\hline Resultados expressos em base úmida. & & & \\
abcd & & &
\end{tabular}

O teor de umidade dos biscoitos sem glúten elaborados com farinha de quinua e fécula de batata variou de 2,4 a 3,7\% (Tabela 2). O biscoito tipo cookie elaborado com $50 \%$ de aveia e $30 \%$ de óleo de canola apresentou 6,39\% (PERES, 2010), já os biscoitos com farinha de jatobá elaborados por Silva et al. (1998) apresentaram teores de umidade entre 8,44 e 10,9\%. Provavelmente essas diferenças são consequência dos diferentes ingredientes utilizados na elaboração dos biscoitos, além do processo de fabricação, principalmente em relação às condições de temperatura e tempo de cozimento. De acordo com a Resolução $n^{\circ} 263$, de 22 de setembro de 2005, da Agência Nacional de Vigilância Sanitária (ANVISA), a umidade de biscoitos e bolachas deve ser no máximo de $15 \%$ p/p (BRASIL, 2005). Dessa forma os biscoitos elaborados no presente trabalho estão dentro dos padrões preconizados pela legislação brasileira.

Em relação à concentração de cinzas os valores obtidos, entre 1,3 e 1,9\% (Tabela 2), são semelhantes aos determinados por Cavalheiro et al. (2001) e Ziglio e Bezerra (2007) que elaboraram e analisaram biscoitos com resíduo de soja e com $2 \%$ de farinha de bagaço de laranja, respectivamente, e encontraram teores de cinzas de 1,3\% e 1,85\%. A legislação brasileira (BRASIL, 
1978) determinava que biscoitos deviam ter no máximo 3,0\% de resíduo mineral fixo (cinzas). Embora essa resolução tenha sido revogada, observa-se que os biscoitos de farinha de quinua e fécula de batata elaborados no presente trabalho encontram-se de acordo com esse parâmetro.

Os teores de proteínas dos biscoitos sem glúten elaborados no presente trabalho foram de 5,0 a 7,7\% (Tabela 2). Concentrações protéicas semelhantes, entre 6,76 e 7,26\%, foram encontradas por Rodrigues (2010) para biscoitos de polvilho enriquecidos com farelo de mandioca. Porém, Santos et al. (2011) verificaram em seu estudo sobre as características físico-químicas de biscoitos de buriti com aveia e sem aveia valores de 3,73 e 2,42\%, respectivamente. O baixo teor de proteínas encontrado nesse último trabalho pode ser justificado pelas características dos ingredientes utilizados nas formulações - energéticos e não protéicos.

Os teores de lipídios das quatro formulações de biscoitos variaram entre 16,3 e 19,5\% (Tabela 2). Santos et al. (2011) elaboraram biscoitos de farinha de buriti sem e com adição de aveia e verificaram no primeiro produto a concentração de $16,87 \%$, valor semelhante ao menor teor encontrado nesse trabalho. O biscoito adicionado de aveia apresentou uma concentração de lipídios de $22,46 \%$, que é $17,2 \%$ maior que o valor máximo determinado nas formulações de biscoitos com farinha de quinua e fécula de batata desenvolvidos no presente trabalho. Essa diferença é consequência da maior quantidade de margarina adicionada na formulação do biscoito enriquecido com aveia para a obtenção de uma massa homogênea capaz de ser moldada, além da gordura proveniente da própria aveia adicionada como ingrediente.

\section{Análise sensorial dos biscoitos}

A Tabela 3 apresenta as médias dos resultados da avaliação sensorial dos atributos aparência, sabor, textura e impressão global das formulações elaboradas dos biscoitos sem glúten com farinha de quinua e fécula de batata.

Tabela 3 - Resultados da avaliação sensorial dos biscoitos sem glúten com farinha de quinua e fécula de batata

\begin{tabular}{ccccc}
\hline \multirow{2}{*}{ Atributo } & \multicolumn{4}{c}{ Formulações } \\
\cline { 2 - 5 } & $\mathbf{A}$ & $\mathbf{B}$ & $\mathbf{C}$ & $\mathbf{D}$ \\
\hline Aparência & $6,88 \pm 2,13^{\mathrm{b}}$ & $7,68 \pm 1,62^{\mathrm{a}}$ & $7,29 \pm 1,86^{\mathrm{ab}}$ & $7,63 \pm 1,54^{\mathrm{a}}$ \\
Sabor & $6,57 \pm 2,19^{\mathrm{a}}$ & $7,05 \pm 2,03^{\mathrm{a}}$ & $6,46 \pm 2,26^{\mathrm{a}}$ & $6,88 \pm 1,89^{\mathrm{a}}$ \\
Textura & $7,13 \pm 1,93^{\mathrm{a}}$ & $7,41 \pm 1,52^{\mathrm{a}}$ & $7,23 \pm 1,81^{\mathrm{a}}$ & $7,21 \pm 1,69^{\mathrm{a}}$ \\
Impressão Global & $6,95 \pm 1,93^{\mathrm{a}}$ & $7,32 \pm 1,73^{\mathrm{a}}$ & $7,20 \pm 1,77^{\mathrm{a}}$ & $7,36 \pm 1,63^{\mathrm{a}}$ \\
\end{tabular}

accd Resultados na mesma linha com diferentes expoentes diferem significativamente ( $\leq \leq 0,05)$, conforme resultado do teste Tukey. 
A Figura 1 apresenta a distribuição de frequência das notas obtidas pelos biscoitos sem glúten elaborados com farinha de quinua e fécula de batata em relação aos atributos aparência, sabor, textura e impressão global.

Figura 1 - Distribuição de frequência dos diferentes atributos sensoriais avaliados das amostras de biscoitos sem glúten com farinha de quinua e fécula de batata: (A) aparência, (B) sabor, (C) textura, (D) impressão global

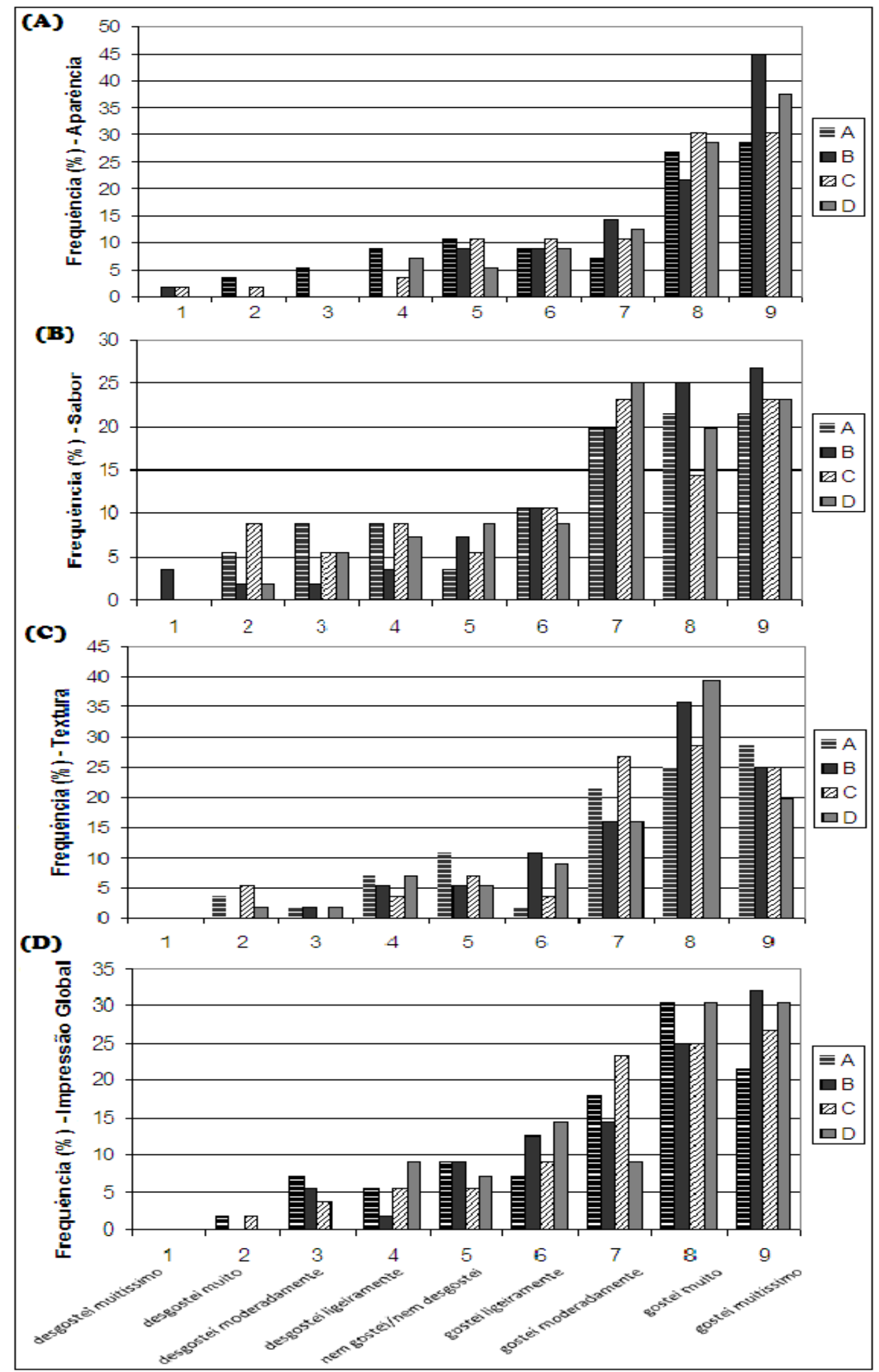


No atributo aparência a amostra que obteve maior aceitação foi a Formulação B (Tabela 3), seguida das Formulações D e C. A amostra com menor pontuação neste quesito foi a Formulação A. Conforme mostra a Figura 1, a Formulação B foi a que apresentou maior número de menções positivas entre os provadores $(89,29 \%)$ para o atributo aparência, além disso, recebeu de 44,64\% dos participantes a classificação de "gostei muitíssimo".

Para o atributo sabor a Formulação B (Tabela 3) teve maior aceitação e 26,79\% dos participantes a classificaram neste quesito como "gostei muitíssimo" (Figura 1). Já a Formulação C não apresentou uma boa aceitação em relação ao sabor, obtendo a menor média de avaliação.

Em relação ao atributo textura (Tabela 3), a amostra que obteve maior aceitação foi a Formulação B (7,41), seguida das amostras C e D (7,23 e 7,21, respectivamente). A amostra que menos pontuou neste quesito foi a Formulação A (7,13). Marcílio et al. (2005) elaboraram 11 formulações de biscoito sem glúten com diferentes quantidades de farinha integral de amaranto e gordura, que foram submetidas a avaliação sensorial por uma equipe de 39 provadores não treinados. A aceitação da textura das 11 formulações variou entre 4,23 e 6,80, inferiores as observadas no presente trabalho para as quatro formulações de biscoito sem glúten com farinha de quinua e fécula de batata.

Em relação ao atributo impressão global, a Formulação B (Tabela 3) obteve a segunda maior média, mas foi a amostra que apresentou a maior proporção (32,14\% dos provadores) na classificação "gostei muitíssimo" (Figura 1).

Os valores médios da aceitação da Formulação B foram superiores as demais amostras para os atributos aparência, sabor e textura (Tabela 3). Apenas em relação à impressão global essa amostra apresentou a segunda maior média, embora não haja diferença significativa $(p \leq 0,05)$ em relação à Formulação D, que apresentou a melhor avaliação. Segundo Lambert et al. (2006) os principais atributos de qualidade dos biscoitos são aparência, sabor e textura.

Os resultados do índice de aceitabilidade dos atributos aparência, sabor, textura e impressão global das quatro formulações de biscoitos sem glúten com farinha de quinua e fécula de batata estão apresentados na Figura 2. 
Figura 2 - Índice de aceitabilidade dos biscoitos sem glúten com farinha de quinua e fécula de batata

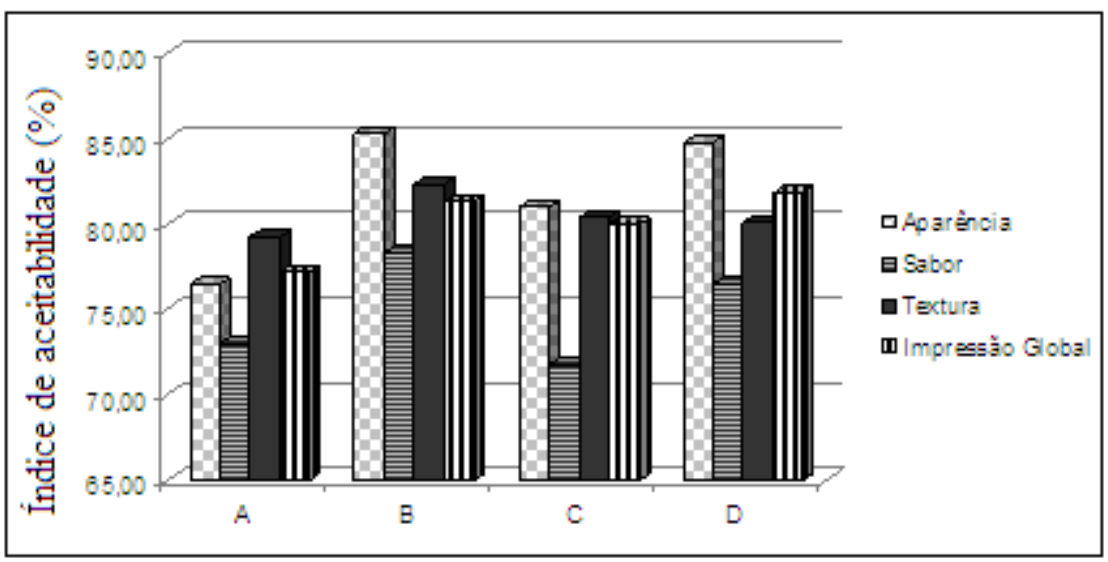

Os resultados do índice de aceitabilidade calculados para a avaliação sensorial dos atributos aparência, sabor, textura e impressão global das quatro formulações de biscoitos sem glúten foram todos superiores a 71\% (Figura 2). Esses índices são muito superiores ao do pão sem glúten com farinha de quinua elaborado por Del Castillo et al. (2009), que obteve somente 40\% de aceitabilidade. Castro et al. (2007) elaboraram diferentes formulações de bolos e biscoitos sem glúten, utilizando grãos, flocos e farinha de quinua, onde os produtos obtiveram índices de aceitabilidade entre $66,33 \%$ a $79,44 \%$.

Segundo Teixeira et al. (1987) para que o produto seja considerado aceito por suas propriedades sensoriais é importante que obtenha um índice de aceitabilidade de no mínimo $70 \%$. Assim, a avaliação sensorial realizada nesse estudo demonstrou que as quatro formulações de biscoito sem glúten elaboradas com farinha de quinua e fécula de batata apresentam potencial para comercialização.

A Figura 3 apresenta a intenção de compra das quatro distintas formulações de biscoito sem glúten elaboradas com farinha de quinua e fécula de batata.

Figura 3 - Intenção de compra dos biscoitos sem glúten com farinha de quinua e fécula de batata

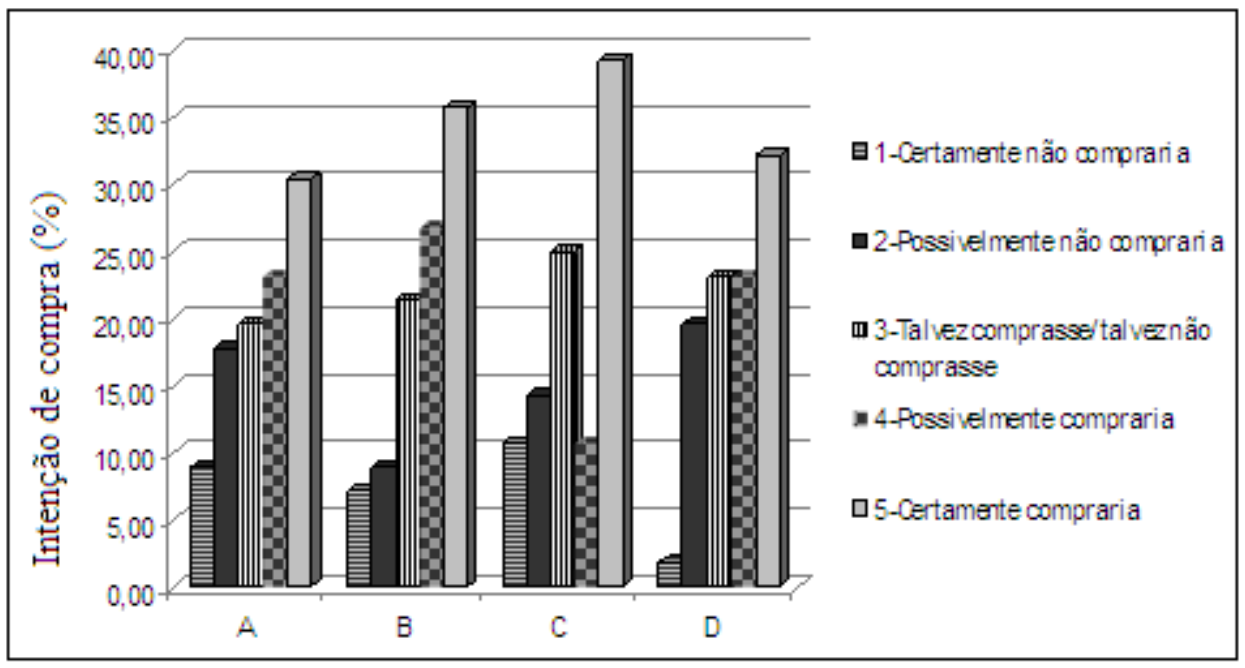


Conforme mostra a Figura 3, as Formulações B, D, A e C apresentaram 62,5; 55,35; 53,57 e $50 \%$, respectivamente, de menções positivas em relação à intenção de compra referidas pelos provadores. De acordo com Aguiar et al. (2008), além das características físico-químicas, o consumidor observa singularidades como aparência externa, cor, firmeza, aroma e sabor no momento da compra de um produto.

A Formulação B, que obteve melhores resultados em relação à avaliação sensorial foi submetida a análise de determinação do teor de fibra alimentar total. Essa amostra apresentou 6,75 g. $100 \mathrm{~g}^{-1}$ de fibra alimentar, podendo então ser classificada como alimento "fonte de fibras", já que este valor enquadra-se no mínimo necessário de $3 \mathrm{~g} .100 \mathrm{~g}^{-1}$ para alimento sólido, conforme descrito na Portaria $\mathrm{n}^{\mathrm{o}} 27$ da ANVISA (BRASIL, 1998). De acordo com Gallagher et al. (2004), é importante que os biscoitos para portadores de doença celíaca apresentem elevados teores de fibra alimentar, uma vez que os produtos sem glúten apresentam baixa teor de fibras por serem oriundos de farinhas refinadas ou amido. A Formulação B apresentou um valor calórico de 472,21 kcal a cada $100 \mathrm{~g}$ de biscoito, sendo que a farinha de quinua agrega valor nutricional aos alimentos (LOPES, 2009).

\section{Conclusão}

Os resultados físico-químicos e sensoriais obtidos nesse estudo demonstraram a viabilidade de elaboração de biscoitos sem glúten com farinha de quinua e fécula de batata. A Formulação B com $31 \%$ de farinha de quinua e $21 \%$ de fécula de batata apresentou melhor aceitação na avaliação sensorial, sendo uma proposta viável para a elaboração de biscoitos sem glúten, possibilitando uma melhoria da qualidade alimentar da população celíaca através do incremento do aporte nutricional de fibra alimentar.

\footnotetext{
Abstract

The cookies represent a practical alternative for nutrient intake, especially carbohydrates and proteins, with a view to ease of transportation and storage, and have long shelf life. On the other hand, celiacs, people with gluten intolerance, because of the limited supply of gluten-free cookies have difficulty in consumption of this food. The objective of this study was to develop and evaluate the physical-chemical and sensory gluten-free cookies. Four different formulations were prepared with quinoa flour and potato starch, which were submitted to physical-chemical determination of moisture, ash, protein and lipids, and sensory attributes of acceptance of appearance, flavor, texture and overall impression, beyond the intention of purchase. The content of ash, protein and lipid formulations of four elaborate ranged from 1.35 to $1.87 \%$ from 5.04 to $7.68 \%$ and 16.26 to $19.52 \%$, respectively. The index score of acceptability attributes of appearance, flavor, texture and overall impression of the four biscuits gluten-free formulations were above $71 \%$. Formulation $B$ with $31 \%$ of quinoa flour and $21 \%$ of potato starch showed better acceptance in the sensory evaluation and $6.75 \%$ of total dietary fiber, with a viable proposal for the preparation of glutenfree cookies, enabling an improved quality celiac diet of the population by increasing the
} 
nutritional intake of dietary fiber. The results of physicochemical and sensory obtained in this study demonstrated the feasibility of preparing gluten-free cookies with quinoa flour and potato starch.

Key-words: biscuits; celiac disease; sensory analysis.

\section{Referências}

AGUIAR, L. P.; FIGUEIREDO, R. W.; ALVES, R. E.; MAIA, G. A.; SOUZA, V. A. B. Caracterização de genótipos de bacurizeiro (Platonia insignis Mart.). Ciência e Tecnologia de Alimentos, v. 28, n. 2, p. 423-428, 2008. http://dx.doi.org/10.1590/S0101-20612008000200024

ALMEIDA, S. G.; SÄ, W. A. C. Amaranto (Amaranthus ssp) e Quinoa (Chenopodium Quinoa) alimentos alternativos para doentes celíacos. Ensaio e Ciência: Ciências Biológicas, Agrárias e da Saúde, v. 13, n. 1, p. 77-92, 2009.

ANIB - Associação Nacional das Indústrias de Biscoitos, disponível em: http://www.anib.com.br/escolha_point_news.asp?id=1463. Acesso em out. 2011.

AOAC. Association of Official Analytical Chemists. Official Methods of Analysis. 15.ed. Arlington: AOAC, p.1298, 1995.

BRASIL. Ministério da Saúde. Agência Nacional de Vigilância Sanitária. Resolução CNNPA. N 12 , de 24 de julho de 1978. Padrões de Identidade e Qualidade para alimentos e Bebidas. Diário Oficial da República Federativa do Brasil, Brasília, DF, 27 de julho de 1978.

BRASIL. Ministério da Saúde. Agência Nacional de Vigilância Sanitária. Portaria N 27, de 13 de janeiro de 1998. Regulamento técnico referente à informação nutricional complementar (declarações relacionadas ao conteúdo de nutrientes). Diário Oficial da República Federativa do Brasil, Brasília, DF, 16 de janeiro de 1998.

BRASIL. Ministério da Saúde. Agência Nacional de Vigilância Sanitária. Resolução RDC N 263, de 22 de setembro de 2005. Regulamento técnico para produtos de cereais, amidos, farinhas e farelos. Diário Oficial da República Federativa do Brasil, Brasília, DF, 23 de setembro de 2005.

CASTRO, L. I. A.; VILA REAL, C. M.; PIRES, I. S. C.; PIRES, C. V.; PINTO, N. A. V. D.; MIRANDA, L. S.; ROSA, B. C.; DIAS, P. A. Quinoa (Chenopodium quinoa Willd): digestibilidade in vitro, desenvolvimento e análise sensorial de preparações destinadas a pacientes celíacos. Alimentos e Nutrição, v. 18, n. 4, p. 413-419, 2007.

CAVALHEIRO, S. F. L.; TININIS, C. R. C. S.; TAVANO, O. L.; CUSTODIO, M. F.; ROSSI, E. A.; CARDELLO, H. M. A. B. Biscoito sabor chocolate com resíduo de soja, "OKARA": Teste afetivo com crianças em idade pré-escolar. Alimentos e Nutrição, v. 12, p. 151-162, 2001.

CZUCHAJOWSKA, Z.; PASZCZYNSKS, B. Is wet gluten good for baking? Cereal Chemistry, v. 73, n. 4, p. 483489, 1996.

DEL CASTILLO, V.; LESCANO, G.; ARMADA, M. Formulación de alimentos para celíacos con base en mezclas de harinas de quínoa, cereales y almidones. Archivos Latinoamericanos de Nutrición, v. 59, n. 3, p. 332-336, 2009.

DESSIMONI-PINTO, N. A. V.; SILVA, V. M.; BATISTA, A. G.; VIEIRA, G.; SOUZA, C. R.; DUMONT, P. V. Características físico-químicas da amêndoa de macaúba e seu aproveitamento na elaboração de barras de cereais. Alimentos e Nutrição, v. 21, n. 1, p. 77-84, 2010.

GALLAGHER, E.; GORMLEY, T. R.; ARENDT, E. K. Recent advancer in the formulation of gluten-free cereal-based products. Trends in Food Science and Technology, v. 15, p. 143-152, 2004. http://dx.doi.org/10.1016/j.tifs.2003.09.012

GUTKOSKI, L. C.; NODARI, M. L.; JACOBSEN NETO, R. Avaliação de farinhas de trigos cultivados no Rio Grande do Sul na produção de biscoitos. Ciência e Tecnologia de Alimentos, v. 23, p. 91-97, 2003. http://dx.doi.org/10.1590/S0101-20612003000400017

IAL - Instituto Adolfo Lutz. Normas Analíticas do Instituto Adolfo Lutz: métodos químicos e físicos para análise de alimentos. v.1, 4 ed., São Paulo, 2005, 1018p. 
LAMBERT, E. A.; PEREIRA, J. G.; LAVINAS, T. S.; SILVA, L. J.; PASSIANOTO, M.; GREGORIO, S. R. Avaliação descritiva quantitativa de biscoito salgado. Revista Universidade Rural: Série Ciências Exatas e da Terra, v. 25, n. 1-2, p. 9-14, 2006.

LOPES, C. O.; DESSIMONI, G. V.; COSTA DA SILVA, M.; VIEIRA, G.; PINTO, N. A. V. D. Aproveitamento, composição nutricional e antinutricional da farinha de quinoa (Chenopodium quinoa). Alimentos e Nutrição, v. 20 , n. 4, p. 669-675, 2009.

MARCILIO, R.; AMAYA-FARFAN, J.; SILVA, M. A. A. P.; SPEHAR, C. R. Avaliação da farinha de amaranto na elaboração de biscoito sem glúten do tipo cookie. Brazilian Journal of Food Technology, v. 8, n. 2, p. 175-181, 2005.

PERES, A. P. Desenvolvimento de um biscoito tipo cookie enriquecido com cálcio e vitamina D. Curitiba, 2010. 93 f. Dissertação (Mestrado em Tecnologia de Alimentos) - Universidade Federal do Paraná.

PEUCKERT, Y. P.; VIEIRA, V. B.; HECKTHEUER, L. H. R.; MARQUES, C. T.; ROSA, C. S. Caracterização e aceitabilidade de barras de cereais adicionadas de proteína texturizada de soja e camu-camu (Myrciaria dúbia). Alimentos e Nutrição, v. 21, n. 1, p. 147-152, 2010.

RODRIGUES, J. P. M. Caracterização e análise sensorial de biscoitos de polvilho enriquecido com farelo de mandioca. Goiânia, 2010. 81 f. Dissertação (Mestrado em Ciência e Tecnologia de Alimentos) - Escola de Agronomia e Engenharia de Alimentos - Universidade Federal de Goiás.

SANTOS, C. A.; RIBEIRO, R. C.; SILVA, E. V. C.; SILVA, N. S.; SILVA, B. A.; SILVA, G. F.; BARROS, B. C. V. Elaboração de biscoito de farinha de buriti (Mauritia flexuosa L. f. ) com e sem adição de aveia (Avena sativa L.). Revista Brasileira de Tecnologia Agroindustrial, v. 5, n. 1, p. 262-273, 2011.

SDEPANIAN, V. L.; MORAIS, M. B.; FAGUNDES-NETO, U. Doença celíaca: a evolução dos conhecimentos desde sua centenária descrição original até os dias atuais. Arquivos de Gastroenterologia, v. 36, n. 4, p. $244-257$, 1999. http://dx.doi.org/10.1590/S0004-28031999000400013

SILVA, M. R.; SILVA, M. A. A. P.; CHANG, Y. K. Utilização da farinha de jatobá (Hymenaea Stigonocarpa Mart.) na elaboração de biscoitos tipo cookie e avaliação de aceitação por testes sensoriais afetivos univariados e multivariados. Ciência e Tecnologia de Alimentos, v. 18, n. 1, 1998. http://dx.doi.org/10.1590/S0101-20611998000100007

SILVA, T. S. G.; FURLANETTO, T. W. Diagnóstico de doença celíaca em adultos. Revista da Associação Médica Brasileira, v. 56, n. 1, p. 122-126, 2010. http://dx.doi.org/10.1590/S0104-42302010000100027

SIMABESP. Sindicato da Indústria de Massas Alimentícias e Biscoitos no Estado de São Paulo, disponível em: <http://www.simabesp.org.br/info.asp>. Acesso em out. 2011.

SPEHAR, C. R. Adaptação da quinua (Chenopodium quinoa Willd.) para incrementar a diversidade agrícola e alimentar no Brasil. Cadernos de Ciência \& Tecnologia, v. 23, n. 1, p. 41-62, 2006.

TEIXEIRA, E.; MEINERT, E. M.; BARBETTA, P. A. Análise Sensorial de Alimentos. Florianópolis: Editora da UFSC, 1987.

ZIGLIO, B. R.; BEZERRA, J. R. M. V. Elaboração de biscoito com adição de resíduos (farinha de bagaço de laranja). Anais do XVI EAIC. 2007, disponível em: 〈http://www.eaic.uem.br/artigos/259.doc〉. Acesso em nov. 2011. 